\title{
Histórico do manejo de Macrófitas Aquáticas no Reservatório Guarapiranga
}

\author{
Admilson Clayton Barbosa ${ }^{1}$ \\ Ivan Chami Gentil ${ }^{1}$, \\ ${ }^{1}$ Empresa Metropolitana de Água e Energia - EMAE \\ Avenida Nossa Senhora do Sabará, 5312 - 04447-900 - São Paulo - SP, Brasil. \\ admilson.barbosa@emae.com.br \\ ivan.gentil@emae.com.br \\ ${ }^{2}$ Universidade Santo Amaro - UNISA \\ Rua Professor Enéas de Siqueira Neto, 340 - 04829-300 - São Paulo - SP, Brasil. \\ ivancgentil@yahoo.com.br
}

\begin{abstract}
This paper aims to present the history of macrophyte management, highlighting the species Eichhornia crassipes Mart. Solms and Pistia stratiotes Linnaeus, in the Guarapiranga reservoir, from technical documents Company Eletropaulo SA on the management and operation of this reservoir.
\end{abstract}

Palavras-chave: macrophyte, Guarapiranga reservoir, Eichhornia crassipes Mart., Pistia stratiotes Linnaeus.

\section{Introdução}

O reservatório do Guarapiranga é um dos principais mananciais da Região Metropolitana de São Paulo, abastece aproximadamente quatro milhões de pessoas. É também o mais ameaçado, estimasse que residem aproximadamente 800 mil pessoas ao redor do reservatório. Em 2003, mais da metade da área do reservatório encontrava-se alterada por atividades humana. No período entre 1989 e 2005 a área ocupada pelo reservatório diminuiu consideravelmente. A diminuição da quantidade de água envolve algumas questões como o aumento na quantidade de macrófitas que impedem a navegabilidade onde acarretam problemas de captação de águas e no manejo do reservatório (ISA, 2006), outra questão a ser considerada em reservatórios de água para abastecimento e geração de eletricidade, são as dificuldades relacionadas às operações de barragens, os bloqueio de sumidouros e o aumento na manutenção de turbinas (PITELLI, 1998; WHATELY e CUNHA, 2006).

Embora sua proliferação seja uma resposta da natureza aos ambientes poluídos, por se alimentar de matéria orgânica e fósforo e, em suas raízes ficar retido material em supersão e absorver metal pesado da água, os problemas a ela associada ainda é maior que os benefícios (CAVENAGHI et al., 2005; ESTEVES, 1998; PEDRALLI, 2003; POMPÊO, 1996).

Outro fator muito relevante é o fato das raízes servirem de habitat para larvas de insetos e as folhas de abrigo aos insetos adultos. As espécies mais recorrentes são do gênero Mansonia e Culex sp., vetores de doenças e de transtornos sociais (NATAL et al.,1991).

Sendo assim, este trabalho fará uma apresentação sobre o histórico de ocorrência de duas espécies de macrófitas Eichhornia crassipes, aguapé e a Pistia stratiotes, alface-d'água no Reservatório do Guarapiranga, concluindo com uma breve discussão sobre o assunto.

\section{Revisão Bibliográfica}

\subsection{Plantas aquáticas - macrófitas}

Segundo Esteves (1998) as primeiras menções ao termo macrófitas aquáticas foi usada no ano de 1938 por Weaver e Clements, que as definiram como plantas herbáceas que se desenvolvem na água, em solos cobertos ou saturados por água. Neste grupo estão incluídos os vegetais que vão desde macro-algas (gênero Chara) até angiospermas (gênero Typha). São 
consideradas vegetais que, durante o processo evolutivo, retornaram do ambiente terrestre para o aquático, mas que mantiveram algumas estruturas características de vegetais terrestres, como a presença de cutícula e estômatos nas plantas aquáticas emersas.

São vegetais macroscópicos, submersas ou parcialmente submersas, ou ainda flutuantes, que habitam água doce ou salobra, cujas partes realizam fotossíntese permanentemente, ou por diversos meses, todos os anos (PEDRALLI et al., 2003; POMPÊO e MOSCHINICARLOS, 2003).

Devido a grande concentração de matéria orgânica encontrada no Reservatório Guarapiranga, existe uma grande ocorrência de macrófita, onde as que possuem maior ocorrência são a Eichhornia crassipes, aguapé (Figura 1), e a Pistia stratiotes, alface-d'água (Figura 2) (ELETROPAULO, 1981).

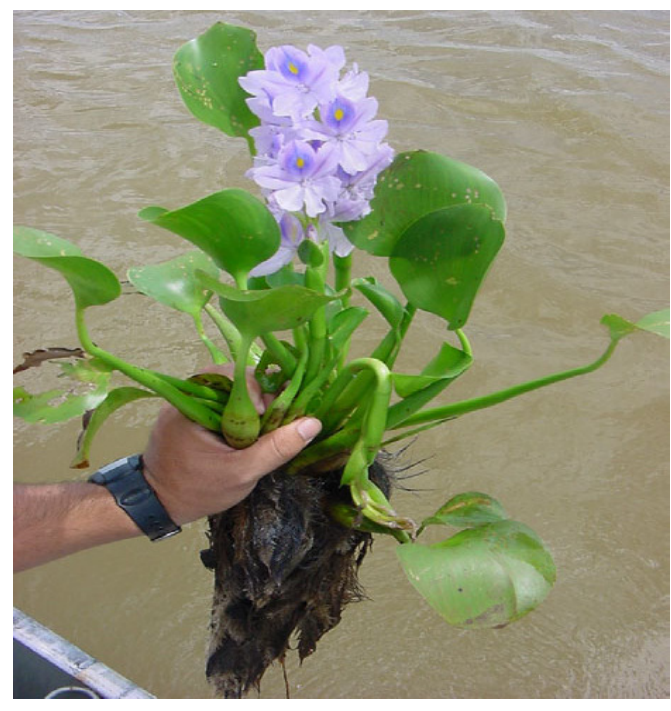

Figura 1: Eichhornia crassipes (CARVALHO et al.,2005).

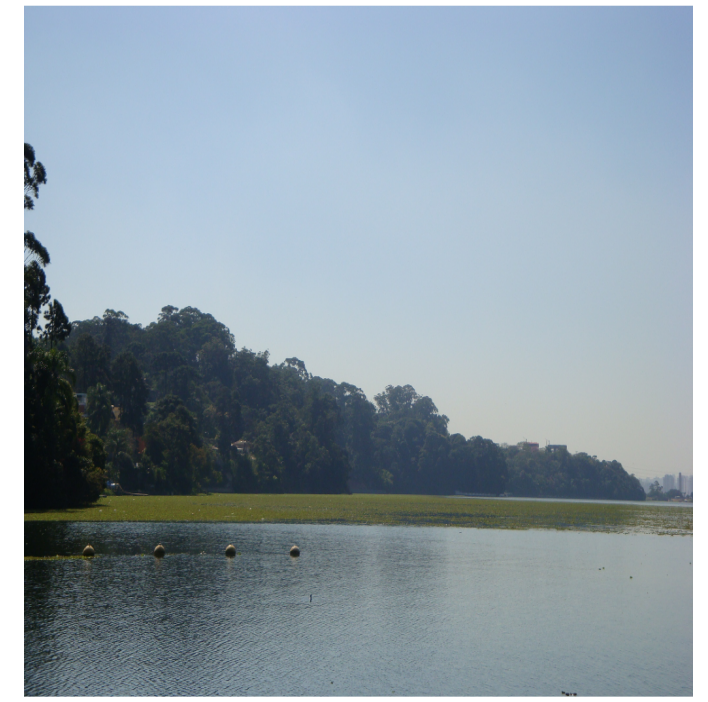

Figura 2: E. crassipers e Pistia stratiotes no reservatório Billings.

\subsection{Biologia}

A macrófita aquática $E$. crassipes é nativa da América do sul tropical e foi introduzida em quase todos os continentes, enquanto que $P$. stratiotes é considerada uma espécie cosmopolita tropical e subtropical (POTT e POTT, 2000).

Ecologicamente, as macrófitas aquáticas podem se constituir no principal produtor de matéria orgânica, atingindo cerca de 100 t de peso seco/ha/ano (PIEDADE et al., 1991), valor superior ao da cana de açúcar, mesmo mediante a aplicação de grandes quantidades de insumos agrícolas. Apresenta importante papel na troca de nutrientes, podendo tornar-se as principais controladoras da dinâmica de nutrientes no ecossistema (JUNK, 1980; POMPÊO, 1996). Dessa forma, participam intensivamente da reciclagem de nutrientes, podendo assimilar elementos retidos no sedimento por intermédio das raízes, os quais são liberados para a coluna de água através da excreção e da decomposição (GRANÉLI e SOLANDER, 1988).

São importantes espécies na cadeia trófica de ecossistemas aquáticos, fornecem abrigo a peixes, insetos, moluscos, e perifiton (POTT e POTT, 2000). Segundo Hamilton (1993), as macrófitas fazem a autodepuração das águas pela assimilação de nutrientes e retenção de sedimentos. 


\subsection{Características gerais da Reprodução de Macrófitas}

Algumas espécies de macrófitas aquáticas possuem sofisticado sistema de polinização cruzada, a heterostilia. A família Pontederiaceae é a única de monocotiledôneas tristílicas, representadas pelos gêneros Eichhornia e Pontederia. Plantas heterostílicas são compostas de flores de diferentes morfas, que diferem nos comprimentos do estigma, estames, tamanho do pólen, com sistema de auto-incompatibilidade. A polinização legítima nas espécies tristílicas (com três morfas) ocorre somente quando flores com estigma longo, médio ou curto recebem pólen compatível, respectivamente, das anteras longas, médias ou curtas. Polinizadores especializados, como a abelha solitária Ancyloscelis gigas, com longa probóscide coberta de cerdas com ganchos, conseguem atingir os diferentes níveis de anteras das folhas tristílicas da E. azurea e efetuar a polinização legítima (ESTEVES, 1998; SANTOS, 1999).

Estudos efetuados em região tropical, particularmente no Brasil, têm demonstrado que o período de crescimento e de mortalidade das macrófitas aquáticas está muito relacionado com a variação do nível da água (JUNK e PIEDADE, 1993; CAMARGO e ESTEVES, 1995, 1996; POMPÊO, 1996).

Algumas espécies de macrófitas aquáticas apresentam picos de biomassa durante o período de cheia (NEIFF, 1975; FRANÇOIS et al., 1989; PIEDADE et al., 1991), enquanto outras, reduções quando cobertas pelas águas, com picos de biomassa durante o período de águas baixas (NEIFF, 1975; JUNK e PIEDADE, 1993).

Provavelmente essa é uma estratégia para minimizar os efeitos da competição. Observaram-se também modificações na composição vegetal (estrutura e dominância) e na biomassa, após o período de cheia. Desta forma, a estrutura da vegetação aquática após a cheia pode ser substancialmente modificada, de acordo com a periodicidade da cheia. Provavelmente a duração da cheia também deve produzir mudanças na composição e nas taxas de crescimento das macrófitas aquáticas (NIEFF, 1975).

\subsection{Comportamento das macrófitas nos reservatórios}

Segundo Pitelli (2006) a maioria dos reservatórios esta sujeito a variação de nível, isso pela sazonalidade e demanda de geração de energia, isso demanda um conhecimento dessa variação e seu efeito sobre as macrófitas, portanto é imprescindível a inclusão deste estudo dentro dos EIA/RIMA ${ }^{1}$. O autor ainda coloca que, a razão desta condicionante se sustenta nos problemas ocasionados por densas infestações de macrófitas aquáticas em vários reservatórios no Brasil.

A distribuição e a presença das macrófitas são determinadas pela concentração dos nutrientes na água, pelo meio suporte onde estão fixadas, profundidades da lâmina d'água, presença ou não de correnteza, índice de turbidez, presença de herbívoros e atividades humanas (APHA, 1995; WOOD e MCATAMNEY, 1996; PITELLI, 2006).

Devido a maior profundidade de penetração da luz, em regiões próximas a barragens, geralmente na zona de desembocadura dos rios em reservatórios as macrófitas aquáticas emersas podem apresentar elevada biomassa onde podem se constituir em importantes produtores de matéria orgânica para o sistema. Nos reservatórios o crescimento excessivo das macrófitas aquáticas pode causar diversos problemas ambientais além de prejuízos à geração de energia e navegação, entre outros usos múltiplos (JUNK et al., 1981).

As maiorias dos problemas causados pelas densas colonizações de macrófitas aquáticas são: alteração das características da água, especialmente redução da disponibilidade de oxigênio dissolvido, alteração das características de navegabilidade e de utilização do corpo hídrico para esportes náuticos, prejuízos à produção de peixes e para a captura do pescado,

\footnotetext{
${ }^{1}$ EIA/RIMA - Estudo de Impacto Ambiental e Relatório de Impacto Ambiental.
} 
criação de condições adequadas para instalação e manutenção de populações de insetos e outros organismos indesejáveis, incluindo vetores de doenças humanas, redução da capacidade de armazenamento e da durabilidade de reservatórios, redução do fluxo d'água e da vida útil de canais de irrigação e drenagem, interferência na captação de água para irrigação e uso público, interferência na produção de energia elétrica, prejuízos à edificações no corpo hídrico, especialmente pontes, aumento das perdas d'água por evapotranspiração, dentre outros (PITELLI, 1998).

\subsection{Reservatório do Guarapiranga}

Segundo Beyruth (2000) o reservatório do Guarapiranga produz água a uma taxa de 10,6 $\mathrm{m}^{3} / \mathrm{s}$, fornecendo cerca de $25 \%$ da Região Metropolitana de São Paulo. O reservatório é a segunda maior fonte de água do Estado (MANCUSO, 1992) é também utilizado para controle de inundações, produção de energia e recreação.

Localiza-se na porção sudoeste da Região Metropolitana de São Paulo, na coordenada $23^{\circ}$ $43^{\prime} \mathrm{S}$ e $46^{\circ} 32^{\prime} \mathrm{O}$, abrange parcialmente os municípios de Cotia, Embu, Juquitiba, São Lourenço da Serra e São Paulo e a totalidade dos municípios de Embu-Guaçu e Itapecerica da Serra, com uma área de drenagem de 639 km² (ISA, 2006).

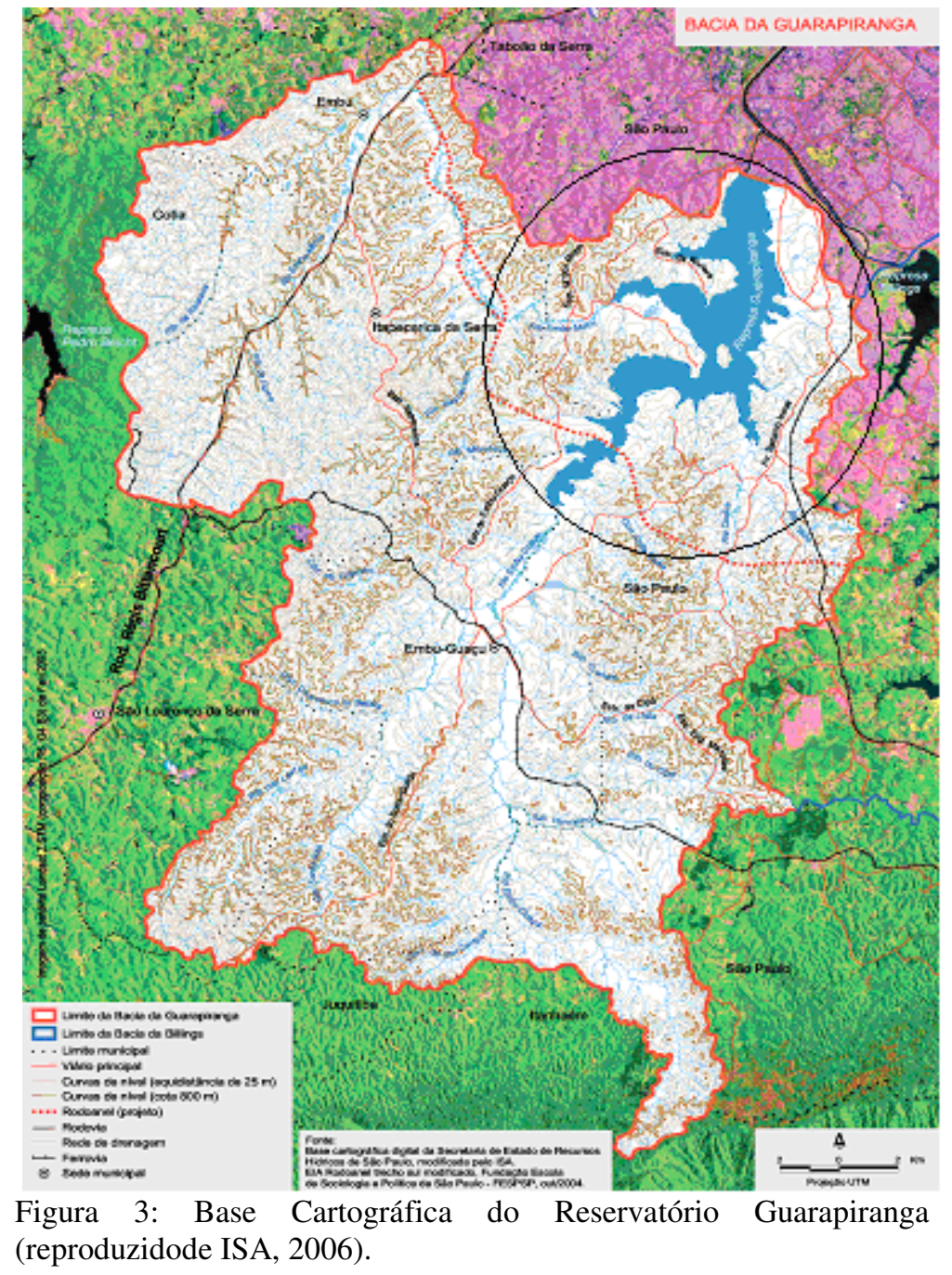

Segundo Whately e Cunha (2006) o reservatório do Guarapiranga foi construído através do represamento do Rio Guarapiranga pela companhia Light \& Power com finalidade 
energética. A partir de 1928, o reservatório da Guarapiranga tornou-se a principal fonte de água para abastecimento público de São Paulo, mediante o fornecimento de 86,4 milhões de litros de água por dia (ISA, 2006). Ainda de acordo com Whately e Cunha (2006) em 1958, na época das cheias o nível do reservatório era mantido em níveis bem abaixo do máximo, possibilitando a regularização das enchentes.

Os primeiros alertas para a degradação da qualidade da água e da região da bacia foram feitos na década de cinqüenta em relação ao esgoto. No final dos anos 80 a ocupação do entorno já causava impactos na represa onde a floração de algas resultantes da grande quantidade de matéria orgânica proveniente do despejo de esgotos na água causaram entupimento dos filtros na captação da água, e ameaçaram o abastecimento de água de três milhões de pessoas. Uma grande mortandade de peixes, noticiadas em todos os veículos de comunicação, deu o alerta sobre a saúde no reservatório. No inicio de 2006, ano do centenário da Guarapiranga, foi aprovada uma lei para o Guarapiranga que tem como objetivo proteger e recuperar a região, constitui o marco inicial para reverter o processo de degradação e garantir o uso deste importante reservatório para abastecimento público (ISA, 2006).

No início de 1959 foi detectada no Embu-Mirim, a presença da variedade de aguapé denominada aguapé de cordão (Eichhornia azurea Kunth), ocupando a área de apenas $800 \mathrm{~m}^{2}$. Em 1979 foi efetuada a retirada mecânica da maioria dessas plantas e até o momento não se notou a proliferação dessa espécie para o restante do reservatório, permanecendo confinada naquele local. Concomitante com o aumento da população dos mananciais do Reservatório, nos últimos anos têm-se observado o aparecimento do aguapé normal formando pequenas moitas isoladas junto às margens, em pontos que coincidem com acúmulos de lixo e detritos, não se caracterizando como infestação. A partir de 1980 foi registrada grande proliferação de algas nas águas do Reservatório, sendo o seu controle executado pela SABESP, que utiliza essas águas para fins de abastecimento (ELETROPAULO, 1982; 1983).

Ao longo dos anos a Eletropaulo utilizou-se de vários processos para manter sob controle a infestação de plantas aquáticas em seus reservatórios: Processo manual que era utilizado para a remoção de pequenas quantidades de plantas esparsas em locais de fácil acesso. $\mathrm{O}$ lança-chamas, de forma experimental no Reservatório Pirapora em 1957, mas o resultado não foi satisfatório. A remoção com escavadeiras, onde o processo é adotado até a presente data no Canal Pinheiros, para remover plantas aquáticas, bem como lixo e detritos acumulados junto as cercas flutuantes existentes no Canal. O processo químico que foi o processo com maior eficiência, pois os demais eram aplicáveis somente em áreas restritas e o controle biológicos que consistia no povoamento de peixes adequados as suas condições, tendo por objetivo o incremento das atividades de pesca (ELETROPAULO, 1982; 1983).

Em agosto de 2009, no Ciclo de Conferência de Gestão Ambiental e Seminário de Monitoramento e Manejo de Macrófitas Aquáticas em Represas Brasileiras, organizado pela SABESP em sua sede na cidade de São Paulo, foram apresentados por pesquisadores da UNESP e UFSCar diversos trabalhos sobre macrófitas, incluindo modelagem matemática para o reservatório, mostrando importantes tendências para o manejo do Reservatório, considerando o ciclo hidrológico, dinâmica e biota do Reservatório, indicando que a melhor técnica para o controle de macrófitas no Guarapiranga seria a que integra e conheça as variáveis operacionais e ecológicas deste ecossistema (SABESP, 2009).

\section{Metodologia}

Esta pesquisa foi realizada a partir de leitura dos relatórios sobre manejo do Reservatório Guarapiranga, elaborado pela Eletropaulo S.A. no período de 1980 a 1986 disponibilizadas nos arquivos da Empresa Metropolitana de Águas e Energia, e em outras fontes disponíveis. 


\section{Discussão}

Segundo Welch (1980) as macrófitas podem acelerar o envelhecimento de um lago provocando aumento na velocidade do processo de assoreamento, por abrigar e consolidar sedimento, já que um lago, do ponto de vista geológico, é um elemento transitório e está gradualmente sendo preenchido.

Para o manejo das macrófitas aquáticas em reservatórios, efetuar o controle em grande escala de fatores ambientais como a temperatura, precipitação e disponibilidade de nutrientes torna-se muito difícil (POMPÊO, 1996; POMPÊO e MOSCHINI-CARLOS, 2003).

Ainda segundo Pompêo (2006) a turbulência da água, ocasionada principalmente pela ação do vento, também não é de fácil controle, tendo que ser levado em consideração a forma, o tamanho e como o reservatório está encravado no relevo regional. Por outro lado, na maioria dos reservatórios é tecnicamente possível efetuar o controle da altura da lâmina d'água através da alteração da vazão. Esse procedimento permite prever as profundidades da massa d'água e da penetração da luz no corpo do reservatório.

Desta forma, a manutenção do nível da água do reservatório em cotas que altere o padrão sazonal histórico da profundidade da água e da penetração da luz poderá interferir no desenvolvimento das macrófitas aquáticas, proporcionando modificações na área potencialmente colonizável nas margens para as emersas e na intensidade da radiação fotossinteticamente ativa para as submersas (ELETROPAULO, 1983; POMPÊO, 1996;).

Segundo Beyruth (1992) ficou evidente a necessidade de proteção vegetal arbustiva nas margens do lago, paralelas ao rio, evitando a entrada de massas de macrófitas para o mesmo nos períodos de enchente. Essa entrada poderia ser danosa ao contribuir para o ingresso dessas massas vegetais no reservatório de Guarapiranga.

A restauração do reservatório Guarapiranga tornou-se muito complicada por tratar-se de um corpo d'água de grande porte, onde algumas das soluções mais comuns são ineficazes como a remoção mecânica, que se torna um processo de alto custo, e o combate com substâncias químicas, como por exemplo, o 3,4D ou outros contaminantes, que põe em risco o abastecimento público de água (ELETROPAULO, 1982; WHATELY e CUNHA, 2006; ISA, 2006).

Uma das medidas de controle de macrófitas, esta implicitamente ligada a qualidade das Águas do Manancial, que pode ser melhorada a partir de medidas de educação ambiental para a população, aplicar as legislativas especificas já existentes e elaboração de programas de gerenciamento de bacias e saneamento. Alguns dos melhores resultados encontrados sobre medidas de controle começaram cedo e por longo tempo antes que uma hiper eutrofização ocorresse. As autoridades de recursos hídricos tendem a contribuir também com estações de tratamentos de esgotos com adequada remoção de nutrientes, ou seja, uma percepção pública maior com a qualidade da água. Para que ocorra sucesso deve-se ocorrer uma forte parceria entre os cidadãos e as estratégias de gerenciamento ambiental.

Em consequiência torna-se pertinente os atuais trabalhos realizados pela SABESP em parceria com as Universidades UNESP Botucatu e UFSCar, no sentido de conhecer a dinâmica do Reservatório, a biologia e ecologia das espécies para realizar o manejo integrado das espécies com a operação do Reservatório (SABESP, 2009).

\section{Conclusão}

As macrófitas são plantas que aparecem naturalmente nos reservatórios. Ecologicamente desempenham funções importantes dentro dos ecossistemas aquáticos. Porém as condições de degradabilidade desses ambientes sejam por poluição ou por assoreamento potencializa sua propagação e crescimento, tornando-se um problema que põe em risco a operação, manejo e vida útil dos reservatórios. 
Não há uma única solução para tratar esse problema, que só poderá ser solucionado a partir do manejo integrado para o controle das macrófitas e conhecimento da dinâmica dos reservatórios, sendo essa uma solução que vem sendo estudada para o Reservatório Guarapiranga.

\section{Referências}

APHA; AWWA \& WPCF. Standard methods for the examination of water and wastewater. 19 ed, Washington D. C./USA, American Public Health Association, 1995.

BEYRUTH, Z. Macrófitas aquáticas de um lago marginal ao rio Embu-mirim, São Paulo, Brasil. Rev. Saúde publ., São Paulo. 1992. v. 26, n 4, p 272-82.

BEYRUTH, Z. Distúrbios periódicos, gradiente trófico e fitoplâncton, características relacionadas ao crescimento de cianobactérias no Reservatório do Guarapiranga, São Paulo, Brasil. Hydrobiologia v. 424, p 51-65, 2000.

CAMARGO, A.F.M.; ESTEVES, F.A. Biomass and productivity of aquatic macrophytes in Brazilian lacustrine ecosystems. In: Tundisi, J.G.; Bicudo, C.E.M.; Matsumura-Tundisi, T., Limnology in Brazil. São Paulo: ABC/SBL, p. 137-149. 1995.

CAMARGO, A.F.M. \& ESTEVES, F.A. Influence of water level variation on biomass and chemical composition of the aquatic macrophyte Eichhornia azurea (Kunth) in an oxbow lake of the Rio Mogi-Guaçu (São Paulo, Brazil). Arch. Hydrobiol., v. 135, n 3, p 423-432. 1996.

CARVAlHO, F.T.; VELINI, E.D. \& MARTINS, D.. Plantas aquáticas e nível de infestação das espécies presentes no reservatório de Bariri, no Rio Tietê. Planta daninha. 2005, v. 23, n.2, p. 371-374.

CAVENAGHI, A.L., VELINI, E.D., NEGRISOLI, E., CARVALHO, F.T., GALO, M.L.B.T.,TRINDADE, M.L.B.7, CORREA, M.R.; SANTOS, S.C.A. Monitoramento de problemas com plantas aquáticas e caracterização da qualidade de água e sedimento na UHE Mogi-Guaçu. Planta Daninha, Viçosa-MG, v. 23, n. 2 , p. $225-231,2005$

ELETROPAUlo. Plantas aquáticas (Reservatório Billings, Pedras e Pirapora), Parte III - Anexos. São Paulo. Eletropaulo Eletricidade de São Paulo S.A. 1981. p 1-20.

ELETROPAULO. Relatório informativo de acompanhamento pela CETESB do controle de plantas aquáticas com uso de herbicidas. São Paulo. Eletropaulo Eletricidade de São Paulo S.A. 1982. p 1-13.

ELETROPAULO. Relatório de Evolução, estado atual e métodos de controle das plantas aquáticas nos reservatórios da Eletropaulo. São Paulo. Eletropaulo Eletricidade de São Paulo S.A. 1983. p 4-9.

ESTEVES, F.A. Fundamentos em Limnologia. 2a ed.Rio de Janeiro: Interciência., 1998. p 575.

FRANÇOIS, J.; RIVAS, A.; COMPERE, R. Le pâturage semi-aquatique à Echinochloa stagnina (RETZ.) P.BEAUV. Etude approfondie de la plante "bourgou" et dês bourgoutières situées en zone lacustre du Mali. Bull. Rech. Agron. Gembloux. 1989. v. 24, n 2, p 145-189.

GRANÉLI, W.; SOLANDER, D. Influence of aquatic macrophytes on phosphorus cycling in lakes.Hydrobiologia, 1988. v. 170, p 245-266.

HAMILTON, S.K. Características limnológicas de importância para as plantas aquáticas no Pantanal. In: Encontro de botânicos do centro oeste, 2., 1993, Corumbá. Resumos. Brasília: SBB; Corumbá: UFMS/CEUC, 1993. p 14.

ISA. Proposições de ações prioritárias para garantir água de boa qualidade para abastecimento público. In Seminário Guarapiranga. São Paulo. Instituto Socioambiental. 2006. 
JUNK, W .J.; PIEDADE, M.T.F. Biomass and primary-production of herbaceous plant communities in the Amazon floodplain. Hydrobiologia, 1993. v. 263, p 155-162.

JUNK, W.J.; ROBSERTSON, B.A.; DARWICH, A.J.; VIEIRA, I. Investigações limnológicas e ictiológicas em Curuá-Una, a primeira represa hidroelétrica da Amazônia Central. Acta Amazonica, 1981. v. 11, n 4, p 689-716.

MANCUSO, P. S. C. Reuso da água e sua possibilidade na Região Metropolitana de São Paulo. São Paulo. Tese de Doutorado, HSA/FSP/USP. 1992.

NATAl, D.; PAGanelli, C. H.; SAnToS, J. L. F. Composição da População Adulta de Culex (Culex) Quinquefasciatus Say, 1823 Em Ecotopos Próximos A Represa Edgard de Souza, no Município de Santana de Parnaíba, Estado de São Paulo, Brasil. Revista Brasileira de Entomologia. São Paulo: v.35, n 3, p $539-543,1991$.

NEIFF, J.J. Fluctuaciones anuales en la composition fitocenotica y biomassa de la hidrofitia en lagunas islenas del Paraná Medio. Ecosur, 1975. v. 2, n 4, p 153-183.

PEDRALLI, G., Macrófitas aquáticas como bioindicadores da qualidade de água: alternativa para usos múltiplos de reservatórios. In : THOMAZ, S. M.; BINI, L.M., Ecologia e manejo de macrófitas aquáticas, $1^{\text {a }}$ Ed., Maringá PR, Editora EDUEM, 2003, p. 171-188.

PIEDADE, M.T.F.; JUNCK, W.J.; LONG, S.P. The productivity of the $\mathbf{C 4}$ grass Echinochloa polystachya on the Amazon floodplain. 1991Ecology, v 72, n4, p 1456-1463.

PITELLI, R.A. Macrófitas Aquáticas do Brasil, na condição de problema. In: Workshop Controle de Plantas Aquáticas, 1998, Brasília. Resumos. Brasília: IBAMA, 1998. p.19.

PITELLI, M.C.R.L Abordagens multivariadas no estudo da dinâmica de comunidades de macrófitas aquáticas. Botucatu SP, Ed UNESP, 2006.

POMPÊO, M.L.M.; HENRY, R. Variação sazonal dos teores de N e P no sedimento do rio Paranapanema (zona de desembocadura na represa de Jurumirim, SP). Anais doI Simpósio de Ciências da engenharia Ambiental, III Simpósio do Curso de Ciências da Engenharia Ambiental, São Carlos, CRHEA/EESC/USP, 1996. p. 135-137.

POMPÊO, M. L. M.; MOSCHINI-CARLOS, V. Macrófitas aquáticas e perifiton, aspectos ecológicos e metodológicos. $1^{\text {a }}$ Ed., São Carlos SP, Ed Rima, 2003.

POMPÊO, M.L.M. Produtividade primária do fitoplâncton da Lagoa Dourada (Brotas, SP). Anais VII Sem. Reg. Ecol., São Carlos, 1996. p. 15-25.

POTT, V.J. \& POTT, A. Plantas aquáticas do Pantanal. Brasília, Embrapa, 404 p. 2000.

SABESP. Ciclo de Conferência de Gestão Ambiental. In: Seminário Monitoramento e Manejo de Macrófitas Aquáticas em Represas Brasileiras. São Paulo, 09/09/2009 disponível em <http://www.sabesp.com.br> acesso em 20/09/2009.

SANTOS, I.A. Polinização de macrófitas aquáticas da família Pontederiaceae. In: Pompêo, M.L.M. (ed.) Perspectiva da Limnologia no Brasil. São Luís: Gráfica e Editora União, 1999. p. 121-129.

WHATELY, M. \& CUNHA, M.P. Guarapiranga 2005: como e porque São Paulo está perdendo este manancial: resultados do diagnóstico socioambiental participativo da bacia hidrográfica da Guarapiranga. São Paulo. Instituto Sociambiental. 2006.

WELCH, P.S. Ecological effects of wastes water. Cambridge, Cambridge University Press. 1980.

WOOD, R. B.; McATAMNEY, C. F. The use of macrophytes in bioremediation .Biotech. Adv., v. 12, p. 653662,1994 